\title{
A INTEGRAÇÃO ENTRE O DIREITO INTERNO E O DIREITO INTERNACIONAL À LUZ DA TEORIA DA CONSTITUIÇÃO: REVISITANDO AS PERSPECTIVAS MONISTA E DUALISTA DO CONFLITO DE NORMAS INTERNACIONAIS
}

\section{THE INTEGRATION BETWEEN DOMESTIC LAW AND INTERNATIONAL LAW BASED ON THE THEORY OF CONSTITUTION: REVISITING THE MONISTIC AND DUALIST THEORIES OF THE CONFLICT OF INTERNATIONAL NORMS}

\author{
João Bruno Farias Madeira ${ }^{1}$ \\ Manuel Fondevila Marón ${ }^{2}$
}

\section{RESUMO}

A integração entre o direito interno e o direito internacional apresenta uma problemática que se tem buscado resolver, historicamente, através das teorias monista e dualista. O estudo proposto busca repensar a subsunção automática do conflito entre a ordem interna e a ordem internacional ao monismo e ao dualismo, afirmando que tal celeuma deve ser vista à luz da natureza do próprio Direito enquanto sistema integrado e sob o olhar dos fundamentos de existência do direito internacional. Preocupado com a unidade, coerência e completude do ordenamento jurídico, apresenta-se uma nova teoria, denominada integracionismo.

Palavras-chave: Conflito de normas. Monismo. Dualismo. Integracionismo. Direito internacional.

\begin{abstract}
The integration between domestic law and international law represents a problem that has been sought historically through monist and dualist theories. The proposed study seeks to rethink the automatic subsumption of the conflict between the internal order and the international order to monism and dualism, it's stating that such excitement must be seen based on the nature of Law itself as an integrated system and under the watchfulness of the foundations of the existence of law International. Concerned with the unity, coherence and completeness of the legal system, a new theory, called integrationism, is presented.
\end{abstract}

Keywords: Conflict of norms. Monism. Dualism. Integrationism. International right.

\footnotetext{
${ }^{1}$ Mestrando em Direito e Instituições do Sistema de Justiça pela Universidade Federal do Maranhão UFMA, São Luís, (Brasil). Especialista em Direito e Comércio Internacional (UAU). Professor de Direito Internacional (IFES). Analista Judiciário (TJMA). E-mail: jbfmadeira@gmail.com

${ }^{2}$ Doutor em Ciências Políticas e Direito pela Universidade Nacional de Educação - UNED, Madri, (Espanha). Professor Permanente no Programa de Pós-Graduação em Direito da Universidade Federal do Maranhão - UFMA. E-mail: m.fondevila.m@gmail.com
} 


\section{INTRODUÇÃO}

A discussão fomentada neste artigo retoma a histórica problemática do relacionamento entre o direito interno e o direito internacional. Embora comporte considerações de caráter monográfico, optou-se por fazer um recorte do tema, neste estudo, apresentando, com base na metodologia de pesquisa bibliográfica e de análise documental, o problema do conflito entre a norma interna e a norma internacional com vias a mensurar a sua aplicação no seio do Estado atual. Para tanto, é trazido, de início, o questionamento acerca da efetiva existência de um ou mais ordenamentos jurídicos (interno e internacional) hábeis a subjugar, simultaneamente, o Estado, não obstante a clássica unidade atribuída ao Direito.

O problema de pesquisa também é enfrentado com base no debate jusinternacionalista acerca do fundamento de obrigatoriedade da norma internacional, partindo a pesquisa, nesse pormenor, do embate entre as doutrinas voluntarista e objetivista tradicionais, as quais, conforme se verá, têm servido como pano de fundo para as soluções historicamente consagradas ao impasse do conflito de normas quanto à sua origem (interna ou internacional), lastreando as teorias monista e dualista de integração de normas jurídicas.

A solução a esse conflito é, no entanto, polêmica e seu tratamento reveste-se de grande importância investigativa em função do relevo que o direito internacional vem adquirindo no cenário jurídico corrente. Não mais como mero marco disciplinador do dinamismo das relações internacionais entre Estados, mas, em especial, como um carreado de parâmetros que permite que relações entre pessoas e povos se desenvolvam num quadro de estabilidade e obediência a valores aos quais a sociedade internacional atribui maior destaque.

Justifica-se, desse modo, a pesquisa em razão da alteração dos paradigmas do próprio direito internacional, vocacionado a contemplar, hodiernamente, uma gama cada vez maior de direitos que ultrapassam a esfera externa do Estado e que, por via de consequência, trazem uma intersecção cada vez mais vívida com o direito interno, à luz de mecanismos de integração supranacional que impõe uma necessidade diuturna de ponderação de como as normas internacionais devem se posicionar nos ordenamentos jurídicos vigentes.

Como pressuposto para a solvência desse impasse, leva-se em conta os meandros do direito internacional geral e a sua inter-relação com a Teoria da Constituição. Toma-se por base a externalização do direito das gentes em uma de suas manifestações pontuais, a norma internacional, considerada em sua acepção tanto de norma dispositiva (tratados internacionais regulares), quanto de norma imperativa (jus cogens), e, de outra face, contempla-se o contexto 
do direito interno, utilizando-se como escopo a ideia de norma interna, constitucional e infraconstitucional, presente nos ordenamentos jurídicos ocidentais.

Tal preocupação quanto à norma e ao ordenamento jurídico nesse estudo do conflito entre o direito interno e o direito internacional, mais do que reduzir o Direito a mera perspectiva normativo-positivista, advém da necessidade de reconhecer que tais elementos são centrais para a obtenção de respostas ao problema de pesquisa apresentado, já que as condutas dos Estados, que se manifestam, como regra, por tais aportes jurídicos, são essenciais para a formação e a aplicação das citadas normas. Pretensão essa que subsidia, conjuntamente, o questionamento de se as soluções para suprir essa necessidade dialógica entre o direito interno e o direito internacional se mostram suficientes nas doutrinas tradicionais.

\section{O PROBLEMA DO CONFLITO ENTRE NORMAS DE DIREITO INTERNO E DE DIREITO INTERNACIONAL}

Em um mundo cada vez mais integrado, o direito internacional tem se mostrado com um papel relevante na dinâmica das relações ultrafronteiriças e com um impacto direto no âmbito interno dos Estados. A globalização, os direitos humanos e a consequente possibilidade de maior interação entre pessoas de nacionalidades diversas no território de dada soberania impõem que as relações entre indivíduos sejam imediatas e dinâmicas e exigem uma pronta resposta para tais intersecções pelo direito internacional, fomentando uma aproximação necessária entre a norma internacional e os sistemas jurídicos dos Estados.

Em contrapartida, vários atos vinculados ao direito internacional também dependem da observância de normas internas. A competência para a celebração de tratados internacionais, por exemplo, tem, via de regra, as autoridades habilitadas para esse fim estipuladas pela norma nacional, conforme preceituado na Convenção de Viena sobre o Direito dos Tratados, de 1969, em seu artigo 46, 1. A esse ponto soma-se o fato de que a maioria dos compromissos internacionais ainda requer ações das autoridades estatais e a execução de ações dentro dos próprios Estados para ter a sua efetividade satisfeita, reafirmando a necessidade de interação entre a norma interna e o direito internacional.

Em muitas situações concretas, existem, portanto, momentos de aproximação, ou mesmo de contradição ou justaposição, entre o objeto jurídico disciplinado na norma interna e na norma internacional, de modo a caracterizar um verdadeiro conflito de normas jurídicas. Tratam-se, conforme a linha adotada para este estudo, de hipóteses em que ocorrem conflitos 
entre os preceitos de direito internacional e de direito interno, suscitando a necessidade de definir qual norma deverá prevalecer no caso em análise ou se será possível a sua integração.

A questão em apreço é controvertida e passa por temas que envolvem a própria reflexão acerca do lugar de assento da norma jurídica e da real natureza do ordenamento jurídico a ela adstrito. Mais precisamente, perquire-se acerca da plausibilidade da existência, ou não, de uma pluralidade de ordenamentos jurídicos, passíveis de subsidiar a vigência simultânea de um ordenamento jurídico interno e de um ordenamento jurídico internacional.

O primeiro problema a ser enfrentado ao se considerar a existência de dois ordenamentos jurídicos distintos, interno e internacional, é o princípio da unidade do Direito. Esse corolário, além de viabilizar toda a concatenação do sistema jurídico, está estampado como axioma da teoria clássica do ordenamento jurídico, nos moldes colacionados por Bobbio (1995, p. 198), em seu livro $O$ positivismo jurídico:

A teoria do ordenamento jurídico se baseia em três caracteres fundamentais a ela atribuídos: a unidade, a coerência e a completitude; são estas três características que fazem com que o direito no seu conjunto seja um ordenamento e, portanto, uma entidade nova, distinta das normas singulares que o constituem.

De acordo com o pensamento bobbiano, a ideia de unidade mencionada é uma premissa prática de existência do próprio Direito enquanto ciência, assim como é indispensável à implantação e estruturação de qualquer ordenamento jurídico. Esse pensamento encontra grande afinidade com a concepção de que o ordenamento estatal deverá sempre buscar a unicidade do sistema jurídico, por meio da integração entre as normas jurídicas que o compõem, a fim de que o ordenamento em que se inserem não seja fracionado, dúplice ou contenha contradições a ponto de descaracterizar a sua própria natureza jurídica.

Ao conceber a viabilidade desse ordenamento jurídico único, Bobbio (1995, p. 38) reconhece, em sua obra Teoria do ordenamento jurídico, que o mesmo contem, em seu bojo, expedientes reconhecidos e expedientes delegados, ante a capacidade do poder estatal de, ao mesmo tempo, criar normas internas e equacioná-las com as normas advindas da sociedade internacional, na qual é partícipe, sem qualquer antinomia:

A complexidade de um ordenamento jurídico deriva do fato de que a necessidade de regras de conduta numa sociedade é tão grande que não existe nenhum poder (ou órgão) em condições de satisfazê-lo sozinho. Para vir a encontro dessa exigência, o poder supremo recorre geralmente a dois expedientes: 1) A recepção de normas já feitas, produzidas por ordenamentos diversos e precedentes. 2) A delegação do poder de produzir normas jurídicas a poderes ou órgãos inferiores. Por essas razões, em cada ordenamento, ao lado da fonte direta temos fontes indiretas que podem ser distinguidas nestas duas classes: fontes reconhecidas e fontes delegadas. A complexidade de um ordenamento jurídico deriva portanto da multiplicidade das fontes das quais afluem regras de conduta, em última análise, do fato de que essas regras são de proveniências diversas. 
Com a sua teoria, Bobbio (1995, p. 161) não nega a existência de um pluralismo de ordenamentos jurídicos em Estados díspares, apenas o faz no entendimento de que cada ente estatal possui um ordenamento interno próprio, diferente do ordenamento interno dos demais Estados, o qual deverá, em todos os casos, se relacionar através de um intercâmbio dialético entre normas internas e internacionais, com vias a preservar a unidade do Direito.

Reafirma, assim, a existência de um ponto de referência de todas as normas do ordenamento jurídico, bem como um poder originário pelo qual o mesmo pode ser justificado. Para Bobbio (1995, p. 41), esse ponto de referência seria necessário para fundar a unidade do ordenamento, sendo esse poder originário nominado de fonte das fontes, ponderando o autor, entretanto, que "se todas as normas derivassem diretamente do poder originário, encontrar-nosíamos frente a um ordenamento simples, não sendo a realidade assim".

Bobbio (1995, pp. 41-42) defende que a complexidade do ordenamento único deriva do fato de que num ordenamento real as normas afluem através de diversos canais, dependendo historicamente, para tanto, de duas razões fundamentais: a autolimitação (que consistiria no exercício do juízo de limitação do poder através da própria feição interna do ordenamento jurídico) e o limite externo ${ }^{3}$ (que consistiria no reconhecimento de normas internacionais precedentes como limite ao poder originário). Tudo de modo a reforçar a interação indispensável entre os direitos interno e internacional no ordenamento estatal.

Ainda que com fundamentação diversa, mas partindo, todavia, do estudo do Direito em sua percepção fascicular de ordenamento jurídico, Santi Romano (2008, pp. 66-67) desenvolve idêntica preocupação com a unidade do Direito e com a superação do conflito de normas jurídicas dentro do mesmo sistema normativo:

\begin{abstract}
É evidente que se queremos definir todo um ordenamento jurídico não podemos levar em consideração somente às suas partes individuais ou aquelas que assim se creem, ou seja, as normas que ali estão compreendidas, para depois dizer que este é o conjunto destas partes. [...] um ordenamento jurídico no sentido dito não é a soma de várias partes, sejam estas ou não simples normas, mas uma unidade entre si - e uma unidade, note-se bem, não artificial ou obtida através de um procedimento de abstração, mas concreta e efetiva - deve ainda ser reconhecido que este ordenamento é algo de diferente dos elementos materiais que o compõem. Ainda melhor, deve ser considerado o fato de que não é possível ter um conceito adequado das normas que nele estão compreendidas sem antepor o conceito unitário desse.
\end{abstract}

A teor do institucionalismo apregoado por Santi Romano (2008), é possível abstrair a

\footnotetext{
3 "O novo ordenamento que surge não elimina nunca completamente as estratificações normativas que o precederam: parte daquelas regras vêm a fazer parte, através de um reconhecimento expresso ou tácito, do novo ordenamento, o qual, deste modo, surge limitado pelos ordenamentos precedentes" (BOBBIO, 1995, p. 42).
} 
imperiosidade de se conceber o Direito como um sistema único, central e com um ordenamento jurídico conciso para cada soberania. Ordenamento esse que, ao mesmo tempo em que é único, se mostra plúrico, na medida em que contem normas advindas parte do espeque interno, parte do espeque internacional, mas que não se fraciona ou se confunde com qualquer dessas partes.

Fincado nessas premissas, é possível afirmar, de logo, que o conflito entre as normas de direito interno e de direito internacional é apenas aparente. O imbróglio apresentado pode e deve ser equacionado à luz da unidade que é característica de qualquer ordenamento jurídico, sob pena de macular a própria existência do Direito que lhe é inerente.

Sob essa perspectiva, o que resta investigar são quais os mecanismos mais propícios para essa integração do ordenamento jurídico estatal, a fim de lhe promover unidade, mediante o equacionamento das normas de direito interno e internacional. No caso, sem a necessidade de enfrentar questões de ordem pública ou de soberania, posto que o debate de tais temas se mostra esvaziado na medida em que o ordenamento uno de que se fala é produto do próprio Estado soberano e da sociedade internacional na qual está inserido.

\section{OS MECANISMOS DE INTEGRAÇÃO}

Entende-se por mecanismos de integração aqueles que contemplam soluções práticas e/ou doutrinárias para a aparente relação tulmutuosa entre o direito interno e o direito internacional com o fito de dar resposta a que tipo de interação eles mantém entre si. Foge, no entanto, ao objetivo deste artigo analisar todas as doutrinas surgidas para explicar as relações entre os direitos interno e internacional, e nem mesmo é um desígnio perseguido avaliar todos os seus mecanismos de integração. Mesmo porque "se trata de problema dos mais delicados e controvertidos, pois o fundamento atribuído ao direito internacional influi decisivamente na posição eventualmente adotada" (ACCIOLY; SILVA; CASELLA, 2008, p. 210).

Com base nesse corolário, percebe-se que o estudo do fundamento do direito internacional alcança destaque realçado para por fim ao impasse ora apresentado, na medida em que visa determinar o motivo pelo qual as normas internacionais são obrigatórias. Querela essa que, a teor da doutrina majoritária do direito internacional, concentra-se principalmente ao redor de duas teorias: a voluntarista e a objetivista.

A teoria voluntarista é uma corrente doutrinária de caráter subjetivista, cujo elemento central é a vontade dos sujeitos de direito internacional. Para o voluntarismo, os Estados e as organizações internacionais devem observar as normas internacionais por terem expressado 
livremente a sua concordância em fazê-lo, de forma expressa ou tácita. Segundo essa corrente, o direito internacional repousaria no consentimento dos Estados.

A teoria objetivista sustenta que a obrigatoriedade do direito internacional advém da existência de valores, princípios e regras que se revestem de uma importância tal que delas podem depender, objetivamente, o desenvolvimento e a existência da sociedade internacional. De acordo com essa corrente, as normas internacionais surgiriam da própria dinâmica da sociedade internacional e existiriam de maneira independente da vontade dos atores internacionais, colocando-se além da vontade dos Estados.

Amparada nessas premissas, a doutrina examina os mecanismos de integração das normas interna e internacional, com base, de um modo geral, em duas correntes que refletem a sua preocupação com a modulação das teorias voluntarista e objetivista, ao fundamentar o direito internacional: as perspectivas dualista e monista, que serão examinadas a seguir.

\subsection{A Perspectiva Dualista}

O primeiro estudo sistemático do conflito entre a norma interna e a norma internacional foi feito por Triepel (1964), instituindo a perspectiva que futuramente seria denominada dualista $^{4}$, para a qual a noção de direito interno e direito internacional seriam noções diferentes e, em consequência, tratar-se-iam de duas ordens jurídicas diferentes, autônomas e independentes, que não possuiriam qualquer área em comum:

[...] o direito internacional e o direito nacional não são somente diferentes disciplinas jurídicas como também diferentes ordens jurídicas. São dois círculos que, no máximo, se tocam, mas nunca se entrecortam. Assim, de nosso ponto de vista, é de uma perfeita contradição considerar o direito internacional como direito nacional ou vice-versa (TRIEPEL, 1964, p. 111).

Essa posição é fundamentada em três diferenças básicas que existiriam nessas ordens jurídicas: a) na ordem internacional, o Estado seria o único sujeito de direito, enquanto que, na ordem interna, o homem também poderia ser sujeito de direitos; b) a fonte do direito interno seria o resultado da vontade de um Estado, enquanto o direito internacional teria como fonte a vontade dos Estados; c) a estrutura da ordem interna estaria pautada em um sistema de subordinação ao passo que a ordem internacional repousaria sobre o primado da coordenação.

Como consequência dessa concepção, focada em uma independência asséptica entre as duas supostas ordens jurídicas, não haveria qualquer possibilidade de conflito entre as

\footnotetext{
4 "A denominação de dualista para essa concepção foi dada por Alfred Verdross, em 1914, e aceita por Triepel, em 1923” (MELLO, 2004, p. 122).
}

Teorias do Direito e Realismo Jurídico | e-ISSN: 2525-9601 | Curitiba | v. 2 | n. 2 | p. 61 - 83 | Jul/Dez. 2016. 
normas interna e internacional, pois elas estariam inseridas em ordenamentos jurídicos dissociados, o que para Mello (2004, p. 122) conduziria "à denominada 'teoria da incorporação', isto é, para que uma norma internacional seja aplicada no âmbito interno do Estado, é preciso que este faça primeiro a sua ‘transformação' em direito interno”.

Ao lado da teoria preconizada por Triepel (1964), o dualismo ainda foi seguido por significativo rol de autores. De acordo com Mello (2004, p.122), destacam-se nessa seara os trabalhos de Anzilotti - que não obstante a similitude com a teoria anterior, chega a admitir a aplicação do direito internacional pelo direito interno, em alguns casos, sem a devida transformação - e Perassi - que embora defenda a autonomia das ordens jurídicas interna e internacional, sustenta a superioridade do direito internacional em relação aos Estados.

As teorias indicadas, hodiernamente nominadas pela doutrina, juntamente com a proposição de Triepel (1964), de dualismo radical (PORTELA, 2015, p. 52) trazem alguns efeitos práticos comuns para o sistema de normas jurídicas por si abalizado: a) os tratados seriam apenas compromissos assumidos na esfera externa, sem capacidade de gerar efeitos no interior do Estado; b) a eficácia das normas internacionais não dependeria de sua compatibilidade com a norma interna; e c) a necessidade de que o conteúdo dos tratados seja incorporado ao ordenamento interno deveria se dar por meio de lei.

$\mathrm{Na}$ busca pela relativização dessa concepção engessada que, bem da verdade, furta-se de todo propósito de integração entre as normas interna e internacional ao considerá-las inseridas em modelos estanques e em ordenamentos jurídicos distintos e incomunicáveis, buscou-se desenvolver, paralelamente, em especial na realidade brasileira, a tese do dualismo moderado.

Essa linha de pensamento, referenciada por Accioly, Silva e Casella (2008, p. 212), difere da anterior no que tange a ausência da necessidade de que o conteúdo das normas internacionais seja inserido em um projeto de lei interna para que tenha validade em âmbito interno, exigindo tão somente a incorporação dos tratados por intermédio de procedimento específico, distinto do processo legislativo comum. Construção essa que, decerto, tem por fim compatibilizar a premissa objetivista da fundamentação do direito internacional com a perspectiva dualista adotada.

De todo modo, independente da posição dualista seguida, ambas merecem, em maior ou menor grau, acentuada crítica por apresentar erros crassos em sua formulação: a pessoa, natural ou jurídica, assim com as organizações internacionais e certas organizações não governamentais são sujeitos de direito internacional, e não apenas os Estados; o voluntarismo 
é insuficiente para explicar a obrigatoriedade da norma de direito internacional imperativo e o costume internacional; a ideia de coordenação de ordenamentos jurídicos nada mais é do que a sua subordinação a uma terceira ordem jurídica; não é possível dissociar o Estado de seu ordenamento, não cabendo ao mesmo responder por com base em uma norma a si estranha.

\subsection{A Perspectiva Monista}

Como tentativa de resposta à falibilidade da perspectiva dualista, estruturam-se novas teorias a fim de explicar essa inter-relação entre o direito interno e o direito internacional. A principal delas, o monismo, afirma "que o direito constitui uma unidade, um sistema, e que tanto o direito internacional quanto o direito interno integram esse sistema" (BARROSO, 2008, p. 187).

Trata-se de uma teoria que não aceita a existência de duas ordens jurídicas autônomas, independentes e não derivadas. Sustenta, de modo geral, a existência de uma única ordem jurídica, quer se apresente nas relações dentro do Estado, quer nas relações internacionais. Parte-se do ideal de que as normas internacionais não podem ter a sua validade condicionada à introjeção de seu teor no direito interno, sendo desnecessária a feitura de novo diploma legal para esse fim, ainda que se possa condicionar, à luz dessa teoria, a eficácia da norma jurídica à harmonização com o direito interno ou a não contrariedade com preceitos de direito das gentes.

Para definir qual norma deverá prevalecer em caso de conflito entre o direito interno e o direito internacional, foram desenvolvidas duas vertentes distintas dentro do próprio monismo: o monismo internacionalista, no qual se defende a primazia do direito internacional, com o ajuste a ele de todas as ordens internas, e o monismo nacionalista, que pugna pela primazia conferida ao direito interno, com a adoção discricionária dos preceitos de direito internacional (REZEK, 2006, p. 4).

\subsubsection{O Monismo Internacionalista}

A corrente internacionalista do monismo tem em Kelsen $(2003,2001)$ o seu principal expoente. Refere-se a uma teoria segundo a qual o direito internacional se aplica diretamente nas ordens jurídicas dos Estados, independente de qualquer transformação, uma vez que esses mesmos entes, em sua relação com outros sujeitos de direito das gentes, contrairiam compromissos que se interpenetrariam e que somente se sustentariam juridicamente por

Teorias do Direito e Realismo Jurídico | e-ISSN: 2525-9601 | Curitiba | v. 2 | n. 2 | p. 61 - 83 | Jul/Dez. 2016. 
pertencer a um sistema jurídico uno, baseado na identidade de sujeitos e de fontes, as quais seriam sempre objetivas, e não dependentes, em rechaçamento ao voluntarismo estatal (MAZZUOLI, 2011, p. 81).

$\mathrm{Na}$ abordagem preconizada por Kelsen, notadamente, através de obras como Teoria pura do direito e Princípios do direito internacional, desenvolve-se, no que se convencionou chamar de Escola de Viena, a primazia do direito internacional em sua conhecida pirâmide normativa, na qual uma norma tem a sua origem e tira a sua obrigatoriedade da norma que lhe é imediatamente superior. De modo que no vértice dessa pirâmide estaria a norma base, a norma fundamental, que consistiria em uma hipótese lógica (KELSEN, 2011, pp. 221-232).

$\mathrm{Na}$ linha de raciocínio do autor, a antinormalidade de uma norma não significaria que haveria qualquer conflito entre a norma inferior e a norma superior, mas isso apenas traduziria a anulabilidade da norma inferior ou a punibilidade de um órgão responsável (KELSEN, 2011, p. 367). Essa fixação da norma poderia, inclusive, estar ligada a sanções e a própria norma, a qual permaneceria válida em caso de descumprimento, pois a sua anulação só seria possível através de ato jurídico próprio e de procedimento previsto naquela ordem jurídica, como no caso da relação entre o sistema de direito interno e internacional:

Toda a evolução técnico-jurídica apontada tem, em última análise, a tendência para
fazer desaparecer a linha divisória entre Direito Internacional e a ordem jurídica do
Estado singular, por forma que o último termo da real evolução jurídica. [...] existe
uma unidade cognoscitiva de todo o Direito, o que significa que podemos conceber
o conjunto formado pelo Direito internacional e as ordens jurídicas nacionais como
um sistema unitário de normas - justamente como estamos acostumados a considerar
como uma unidade a ordem jurídica do Estado singular (KELSEN, 2003, p. 364).

Kelsen retoma, nesse ponto, o postulado teorético-gnoseológico que condiciona a abrangência de todo o Direito num só sistema, concebendo-o sobre um ponto de vista único, como um todo fechado sobre si. Ao descrever o seu critério de Direito e de ordenamento jurídico como um objeto com uma unidade, aponta que o critério negativo desta unidade seria a ausência de contradição entre normas jurídicas (2003, p. 365). Sustenta que a relação existente entre direito interno e internacional não importaria em conflito, pois a unidade do Direito, levada a cabo, excluiria a integridade desse sistema de normas (2003, p. 365).

Nessa concepção, a própria noção de soberania passaria a ser entendida com certa relatividade e seria dependente da ordem internacional, já que o ordenamento jurídico, em sendo uno, consistiria em uma ordem hierarquicamente superior, pautada na norma internacional, da qual derivaria o direito interno e à qual estaria subordinado. Sob esse cotejo, Kelsen defende, em sua construção teórica, que uma norma interna que contrarie uma norma internacional deverá ser declarada de pronto inválida. 
A tese de Kelsen (2003, pp. 368-369), do ponto de vista científico, sugere a busca pela unidade dos direitos interno e internacional de duas maneiras distintas: ou por meio de dois complexos de normas do tipo dinâmico, como reconhece ser o do ordenamento jurídico internacional em sua relação com o ordenamento jurídico estatal atual, por meio da subordinação de um a outro; ou por intermédio da busca de unicidade de dois ordenamentos situados no mesmo nível com base em outro sistema que estaria em um plano superior, reconhecendo que essa hipótese seria a tendência futura do direito internacional, na construção de um sistema normativo mundial.

Nada obstante, a perspectiva monista internacionalista não se esgota com a visão kelseniana. Verdross (1976, p. 16), por exemplo, defende que o direito positivo, além de ter por fundamento a sociedade, também teria um fundamento normativo que estaria enraizado na natureza social e teleológica do homem, a qual lhe impulsionaria a viver em uma ordem de paz, com superação do que nomeia positivismo jurídico dogmático. Em seu pensamento, a norma fundamental de um ordenamento jurídico deveria seguir essa ideia de Direito, considerada como uma ordem de paz, e não de dominação arbitrária (1976, p. 23).

No tocante, especificamente, à relação entre o direito internacional e o sistema jurídico interno, o autor entende que somente uma teoria poderia revelar a realidade jurídica a fim de solver o conflito entre norma interna e norma internacional. Para Verdross (1976, p. 97), a teoria que encontra, em caráter definitivo, a devida solução para o impasse se funda no sistema jurídico unitário, que seria constituído de ambas as ordens, interna e internacional. Reconhece, assim, tanto o direito internacional, quanto o nacional, não comungando com Kelsen a ideia de invalidade da norma interna contrária à norma internacional, mas apenas a existência de um ato ilícito passível de responsabilização.

Rechaça Verdross (1976, p. 88), ainda, qualquer possibilidade de aplicação da premissa voluntarista do direito internacional, adotando uma teoria que acabou intitulando de monismo moderado. Defende que a adesão do Estado à sociedade internacional se dá de maneira voluntária, sob os cânones preconizados pelo direito natural, destarte, sem a necessidade de reconhecimento ou adesão por parte de cada soberania.

Ante tais ponderações, é possível perceber que, embora os mais notórios representantes da teoria monista internacionalista, Kelsen (2003) e Verdross (1976) apresentam diferentes concepções acerca desse objeto. A construção monista de direito proposta por Kelsen tem por base, inicialmente, a constituição estatal e, posteriormente, com a atualização de sua teoria, acaba por se filiar a ideia de que o direito internacional seria o 
ápice de sua estrutura normativa. Já a construção monista preconizada por Verdross adotou como ponto de partida o direito natural produzido no âmbito da comunidade internacional, possivelmente até influenciando Kelsen em sua parcial mudança de pensamento ${ }^{5}$.

Fato é que em ambas as vertentes há clara defesa de que o conflito entre o direito interno e o direito internacional não quebraria a unidade do sistema jurídico, assim como não haveria quebra do direito estatal quando ocorresse um eventual conflito entre a lei e a Constituição na seara interna, onde não haveria que se falar em desabilitação, por esse fator, de todo o ordenamento jurídico do Estado.

Não bastasse a doutrina, a jurisprudência internacionalista também tem reconhecido a estruturação da teoria monista internacionalista. A mencionada superioridade do direito internacional sobre o direito interno de cada Estado defendida por essa vertente do monismo foi afirmada, desde 1930, pela Corte Permanente de Justiça Internacional, em parecer consultivo, com o seguinte teor: "É princípio geral reconhecido, do direito internacional, que, nas relações entre potências contratantes de um tratado, as disposições de uma lei não podem prevalecer sobre o tratado" (ACCIOLY; SILVA; CASELLA, 2008, p. 211).

Esse primado permaneceu como o primordialmente adotado na seara do direito internacional, a ponto da Convenção de Viena sobre o Direito dos Tratados, de 1969, dispor, em seu artigo 27, que "uma parte não pode invocar as disposições de seu Direito interno para justificar o inadimplemento de um tratado”. Essa tratativa, ao que parece, busca resguardar as bases da convivência internacional, visando considerar a atuação do Estado em sua dimensão externa, e não somente as questões administrativas internas de cada soberania.

\subsubsection{O Monista Nacionalista}

Embora partindo da premissa de que existe apenas uma ordem jurídica, o monismo nacionalista se difere da perspectiva anterior por apregoar a primazia do direito interno do Estado em detrimento da norma internacional. Fundamenta-se a teoria em valores como soberania estatal e em prerrogativas hegelianas que representam o conceito de Estado como a realização plena de seu espírito objetivo, a fim de nele encontrar a sua plena efetivação.

Para Hegel (2010, pp. 257-258), “o Estado é a efetividade da idéia ética” e "um autofim

\footnotetext{
${ }^{5}$ Nesse sentido, Mello (2004, p. 124), para quem “a concepção kelseniana foi denominada na sua primeira fase de teoria da livre escolha; posteriormente, por influência de Verdross, Kelsen sai do seu 'indiferentismo' e passa a considerar a 'Grundnorm' como sendo uma norma de DI: a norma costumeira 'pacta sunt servanda'. [...] Finalmente o mestre de Viena, ainda por influência de Verdros, passou a admitir a possibilidade de conflitos entre as duas ordens jurídicas".
} 
imóvel absoluto em que a liberdade chega a seu direito supremo", sendo esta a razão defendida de seu "espírito objetivo pleno". Justifica, assim, que o Estado não estaria sujeito a nenhum sistema jurídico que não tenha emanado de sua própria vontade, restringindo o direito internacional a um direito interno que os entes estatais aplicariam em suas relações exteriores.

Segundo o pensamento do autor, a soberania externa seria incorporada, portanto, ao direito interno estatal, de maneira a restringir a sua concepção ao ideal de que as relações entre os Estados pertenceriam à soberania interna. Tal qual argumenta, o Estado seria, essencialmente, um ser-para-si, que assumiria dentro de si a diferença subsistente e que seria, com isso, excludente. Através da relação com outros Estados, cada Estado deteria a determinação de sua individualidade, reafirmando, ao mesmo tempo, a sua independência e a sua relativa incorporação nessa pluralidade de Estados (HEGEL, 2010, pp. 321-329).

A perspectiva explanada predominou na prática da convivência internacional a partir da Paz de Vestfália ${ }^{6}$, não obstante a existência de tratados internacionais posteriores que declinassem de modo expresso da existência de uma soberania do Estado irrestrita, como já mencionado. Ademais, essa ideia de que o ordenamento interno é hierarquicamente superior ao internacional e de que há uma prevalência das normas internas em face das internacionais ainda encontra guarida na doutrina atual. Heller (1995), ao criticar as concepções de Estado de Kelsen (2003) e de Schmitt (2011), vislumbra uma maneira distinta de ver o direito internacional, coerente com uma visão de espaço político nacionalista.

Na prática, Heller confere ao direito internacional, em sua noção de soberania estatal, uma posição de subordinação dentro do modelo monista de direito. Defende a primazia do direito nacional sobre o direito internacional, aduzindo que "todo Derecho - incluso el internacional - puede reducirse al Derecho nacional, es decir, al Derecho del Estado soberano" (2015, p. 220). O seu grande contraponto a Kelsen volta-se, portanto, à questão da soberania, uma vez que o autor vienense afirma o predomínio do direito sobre o poder a partir da reconstrução da concepção de Estado como ordenamento jurídico.

Em sua obra, Heller revisita o conceito de soberania $^{7}$, afirmando que o jurista deve partir desse fato para a sua análise da ordem jurídica (1995, p. 91). O autor denuncia o intento

\footnotetext{
${ }^{6}$ A Paz de Vestfália designa uma série de tratados que encerraram a Guerra dos Trinta Anos e reconheceram as Províncias Unidas e a Confederação Suíça, como o Tratado Hispano-Holandês, assinado em Münster, em 1648, que pôs fim à Guerra dos Oitenta Anos, e o Tratado de Vestfália, assinado em Osnabrück, em 1648, que pôs fim ao conflito entre França e Suécia e o Sacro Império Romano-Germânico.

${ }^{7}$ Para Heller (1995, p. 289), a soberania é a propriedade de uma unidade de ação e de decisão universal sobre o território, em virtude do qual, para garantir o direito, se afirma de modo absoluto, circunstancialmente, inclusive contra o Direito.
} 
de Kelsen por supostamente ocultar ou dissolver o conceito de soberania e subsumir o Estado ao ordenamento jurídico (1995, p. 88). Diferente de Kelsen, Heller busca a validez do direito no homem, no povo e em suas vidas, entendendo que o dever jurídico é um produto do ser e que pela norma se dá o ser, o povo, para reger sua conduta (1995, p. 139).

Ressalta o autor que as duas qualidades advindas da soberania, a universalidade potencial e a efetividade atual da decisão destruidora, se reúnem unicamente no Estado soberano, já que não existiria ainda sobre o Estado nenhuma unidade de ação universal capaz de impedir que o ato estatal contrário ao direito se transformasse em direito:

[...] en tanto exista el derecho internacional y en la medida en que no esté sustituido por un estado mundial, tienen que existir estados soberanos, de onde surge la posibilidad de que un acto estatal violador del derecho del estado o del internacional, cree final e inapelablemente um derecho novo (HELLER, 1995, p. 281).

Como consequência dessa perspectiva monista nacionalista, nenhum tratado internacional poderia nascer sem a aprovação de todos os Estados que participassem de sua formação, que unicamente poderia ser objetivada pela ação de unidades de vontades que não estariam subordinadas a outra unidade decisória universal (1995, p. 233). Ao afirmar a soberania do Estado como pressuposto do direito internacional, Heller a entende como uma espécie de capacidade jurídica de ação e como uma esfera de livre ação da competência internacional (1995, p. 279).

A teoria trazida à baila eiva-se, contudo, de uma melhor análise da norma internacional ao condicionar a sua aplicação à utopia de um Estado mundial. Não dá respostas também ao problema apresentado, pois o monismo nacionalista guarda graves problemas em sua construção: a) nega a existência do próprio direito internacional como um direito autônomo, reduzindo-o a um simples direito estatal exterior; b) considera o Estado como detentor de soberania absoluta, retirando a função do direito internacional enquanto mecanismo de limitação externo do poder originário estatal; c) considera que a validade dos tratados repousa na norma interna, o que implicaria em equivocada revogação, modificação ou caducidade da norma internacional toda vez que a norma interna fosse alterada.

\section{A INSUFICIÊNCIA DAS PERSPECTIVAS TRADICIONAIS}

Conforme desenvolvido logo no início do tópico antecedente, os mecanismos de solução para o conflito entre as normas interna e internacional passam pela análise das técnicas de integração da ordem estatal e pelo vislumbre do fundamento do próprio direito internacional. Sob esse aporte, tanto as premissas voluntaristas, quanto as objetivistas, em sua aplicação pura, 
apresentam críticas consistentes na doutrina, as quais se passa a apresentar:

\begin{abstract}
A doutrina voluntarista é criticada por condicionar a regulamentação internacional, inclusive a concernente a matérias de grande importância para a humanidade, à mera vontade dos Estados, normalmente vinculada a inúmeros condicionamentos. A doutrina objetivista, por outro lado, ao minimizar o papel da vontade dos atores internacionais na criação das normas internacionais, coloca também em risco a própria convivência internacional, ao facilitar o surgimento de normas que podem não corresponder aos anseios legítimos dos povos (PORTELA, 2015, pp. 43-44).
\end{abstract}

As ponderações de Portela se equalizam com o fato de que o fundamento do direito internacional inclui, efetivamente, e ao mesmo tempo, elementos voluntaristas e objetivistas. Os Estados, ao passo em que se obrigam a cumprir as normas internacionais com as quais consentiram, não podem se eivar, uma vez insertos na sociedade internacional, em cumprir as normas imperativas ou consuetudinárias que estão inseridas naquele ordenamento jurídico.

O exercício da vontade estatal não pode violar, por exemplo, as normas de jus cogens, tendo em vista que o artigo 53 da Convenção de Viena sobre o Direito dos Tratados, de 1969, prescreve que "é nulo o tratado que, no momento de sua conclusão, conflita com uma norma imperativa de direito internacional geral" e ainda acrescenta:

\begin{abstract}
Para os fins da presente Convenção, uma norma imperativa de direito internacional geral é uma norma aceita e reconhecida pela comunidade internacional dos Estados no seu conjunto, como norma da qual nenhuma derrogação é permitida e que só pode ser modificada por nova norma de direito internacional geral da mesma natureza (BRASIL, 2009, não paginado).
\end{abstract}

Há outros diplomas normativos internacionais que prescrevem idêntica proibição ou mitigam o exercício do direito internacional sob a limitação do direito interno. Acerca, especificamente, da norma de jus cogens, a mesma Convenção de Viena sobre o Direito dos Tratados (BRASIL, 2009, não paginado) ainda pontua, em seu artigo 64, que "se sobrevier uma nova norma imperativa de direito internacional geral, qualquer tratado existente em conflito com essa norma torna-se nulo e extingue-se".

Ao lado dessa perspectiva axiológico-normativa, que faz ressoar a necessidade de uma efetiva dialética entre os fundamentos voluntarista e objetivista do direito internacional, ainda pairam críticas arraigadas aos mecanismos de integração apontados no tópico precedente, por se mostrarem insuficientes o dualismo e o monismo, em maior ou menor grau, para representar o momento atual da sociedade internacional e a dinâmica que ela exerce ante os sistemas normativos dos Estados ${ }^{8}$.

\footnotetext{
${ }^{8}$ Para Mirkine-Guetzévitch (2009, p. 130), "No es posible explicar la realidad internacional indicando que las relaciones entre el Derecho internacional y el Derecho interno se basan en tal o cual concepción teórica: estamos obligados a decir que la realidad jurídica es a la vez monista y dualista, [...]. Insistimos en la necesidad de reconecer la coexistência de estas dos concepciones en la realidad histórica.
} 
Rezek (2006, p. 5) pontua que nem o monismo internacionalista, nem o monismo nacionalista, ou mesmo o dualismo são pensamentos invulneráveis à sopesamentos, assentando que "muito já escreveram os partidários de cada uma delas no sentido de desautorizar as demais". Acrescenta o autor que cada uma dessas três proposições poderiam ser valorizadas em seu mérito se admitido que procurariam descrever o mesmo fenômeno visto de diferentes ângulos.

Apesar da reverberação do posicionamento de Rezek, ousa-se ponderar que mais do que uma simples questão de ângulo, as teorias apontadas acabam por se equivocar ao radicalizar pontos cabais de sua construção (como, por exemplo, a incomunicabilidade entre ordens jurídicas na premissa dualista), não deixando espaço para a realização de adequações à realidade do ordenamento jurídico vigente, nem se amoldando ao fato de que a unidade do ordenamento merece ser preservada, em uma livre dialética entre os poderes de recepção, delegação e os limites internos e externos a si impostos.

Aliás, o próprio Rezek (2006, p. 5) é bem feliz ao apontar algumas das falhas que acometem as teorias em cotejo:

\begin{abstract}
Os dualistas, com efeito, enfatizam a diversidade de fontes de produção das normas jurídicas, lembrando sempre os limites de validade de todo direito nacional, e observando que a norma de direito das gentes não opera no interior de qualquer Estado senão quando este, havendo-o aceito, promove a introdução no plano doméstico. Os monistas kelsenianos voltam-se para a perspectiva ideal de que se instaure um dia a ordem única, e denunciam, desde logo, à luz da realidade, o erro da ideia de que o Estado soberano tenha podido outrora, ou possa hoje, sobreviver numa situação de hostilidade ou indiferença frente ao conjunto de princípios e normas que compõem a generalidade do direito das gentes. Os monistas da linha nacionalista dão relevo especial à soberania de cada Estado e à descentralização da sociedade internacional. Propendem-se, desse modo, ao culto da constituição.
\end{abstract}

Notoriza-se, assim, a necessidade de construção de um mecanismo de integração de normas que supere os paradigmas tradicionais e perceba o direito internacional de um modo mais multifacetado, não apenas como um organismo voltado à realização da atividade externa do Estado, mas como um instrumento que busque regular as relações nas quais a norma internacional se insira e ainda vise tutelar temas de interesse internacional de maneira a nortear a convivência entre os membros da sociedade internacional, que não mais inclui somente os Estados e as organizações internacionais, mas também outras pessoas e entes como os indivíduos, as empresas e as organizações não governamentais.

\title{
5 A SOLUÇÃO DO IMPASSE À LUZ DA TEORIA DA CONSTITUIÇÃO
}

A fim de estruturar uma solução aceitável ao conflito entre a norma interna e a norma 
internacional, entende-se que o melhor caminho para esse desiderato remonta à necessidade de criar uma teoria abalizável na prática e que, ao mesmo tempo, não vilipendie o Direito na sua própria natureza de integralidade e nem desconstrua o ordenamento jurídico enquanto propositura que persegue uma unidade, coerência e completitude.

Faz-se de imediato a necessidade de afastar qualquer perspectiva dualista para a integração de normas ora proposta, tendo em vista que tal perspectiva comete o erro crasso de considerar a coexistência de dois ordenamentos distintos, interno e internacional, que não se intersectariam, descontruindo a noção una de ordenamento estampado na ciência jurídica e afastando qualquer possibilidade de aplicação da norma internacional costumeira, positivada ou mesmo imperativa no cenário interno.

Fincada essa premissa, tem-se que a ordem jurídica é una e, portanto, nesse pormenor, a teoria monista possui alguma guarida, embora não se possa coadunar com o ideal de primazia absoluto, quer da norma interna, quer da norma internacional, que a mesma apresenta. Afinal, o que se verifica, na prática, é que as regras constantes de tratado internacional aprovado e ratificado segundo as regras do ordenamento de dado Estado se inter-relacionam com a lei interna e com elas dialogam sem grandes percalços na maioria dos ordenamentos ${ }^{9}$, seguindose, entretanto, maior problema quanto ao critério utilizado, por alguns países, de que a lei interna poderia substituir tratado em vigor (BARROSO, 2008).

Não faltam teses, todavia, que apregoam a legalidade, a supralegalidade e até mesmo a constitucionalidade do status de ingresso dessas normas internacionais no espeque interno, tendo em vista que se trata de exercício de recepção do poder de delegação do Estado, já explanado na teoria bobbiana, que compete ser elidida em decisão do próprio Estado soberano, observando, em todo caso, a plena aplicabilidade da norma internacional, sob pena de ferir a unidade do ordenamento jurídico.

Bem da verdade, uma lei ordinária contrária ao direito internacional dará ao Estado prejudicado, como regra, o direito de iniciar um processo de responsabilização internacional, notadamente quando essa norma de direito das gentes se dirigir de modo direto ao indivíduo, ao passo que uma norma nacional contrária à lei interna não dá ao Estado o direito análogo ao da hipótese suscitada, mas, tal como a anterior, não eiva o prejudicado de acesso ao Poder

\footnotetext{
${ }^{9}$ No mesmo sentido, Mirkine-Guetzévitch (2009, pp. 132-133), para quem "El monismo no es aún toda la realidad internacional, pero ya es una parte de esta realidad. El monismo no engloba todo el Derecho internacional de nuestra época, pero penetra poco a poco en varias de sus instituciones. Podemos reconecer que la tendencia actual del movimento jurídico internacional es una tendencia monista".
} 
Judiciário, à luz do ordenamento do Estado.

Maior dificuldade se percebe, no entanto, quando o pretenso conflito de normas se dá entre o direito internacional e a Constituição de um Estado. Esse conflito sensível de normas envolvendo o texto constitucional, defende-se, deverá ser resolvido de modo distinto, a depender (a) do momento em que ele se apresenta no caso concreto (antecedente ou posterior à Constituição) ${ }^{10}$, (b) do tipo de norma que está em confronto e (c) da previsão constitucional sobre a inter-relação entre essa norma fundamental e o direito internacional.

Mais do que apregoar tais intersecções, urge justificar, a teor do objeto deste artigo, a utilização desse entendimento à luz da Teoria da Constituição. Para Canotilho (2003, p. 1318), a referida teoria é mais do que uma teoria política, é uma teoria científica do direito constitucional. Aspira ser um estatuto teórico da teoria crítica e normativa da Constituição, no sentido de racionalizar pré-compreensões do intérprete das normas constitucionais, procurando evitar que os seus prejuízos e pré-conceitos jurídicos, filosóficos, ideológicos, religiosos e éticos afetem a racionalidade e razoabilidade indispensáveis à observação da rede de complexidade do estado de direito democrático-constitucional.

A Constituição moderna, na visão de Canotilho (2003, p. 52) seria a ordenação sistemática e racional da comunidade política através de um documento escrito no qual se declarariam as liberdades e os direitos e se fixariam os limites do poder político. Como estrutura de sua definição, Canotilho estabelece a incorporação das seguintes características á Constituição: documento escrito, estabelecimento de direitos fundamentais e as suas garantias e a organização do poder político segundo esquemas tendentes a torná-lo um poder limitado e moderado.

Para o problema de pesquisa proposto, importa destacar dois pontos da teoria apontada: o sentido crítico e normativo de Constituição, no sentido de racionalizar a interpretação constitucional, e a possibilidade de impor limites e moderação ao poder dela decorrente, a fim de sopesar qual a relação da Constituição com as demais normas de direito e, precisamente, qual a sua relação com a norma internacional. Tais premissas, não há que se olvidar, se coadunam perfeitamente com a linha de pensamento adotada de que limites poderão ser impostos, em certas circunstâncias, a própria Constituição para fim de equacionar a unidade

\footnotetext{
${ }^{10}$ Para Barroso (2008, p. 205), "O tratado celebrado na vigência de uma Constituição e que seja com ela incompatível, do ponto de vista formal (extrínseco) ou material (intrínseco), é inválido e se sujeita à declaração de inconstitucionalidade incidenter tantum, por qualquer órgão judicial competente [...]. O tratado que se encontrar em vigor quando do advento de um novo texto constitucional, seja este fruto do poder constituinte originário ou derivado, será tido como ineficaz, se for com ele incompatível".
} 
do ordenamento jurídico.

Nesse ensejo, a teoria de Miranda (2011, p. 182) parece melhor abordar o problema proposto, ao externar que:

Fenômeno inverso ao da irradiação de figuras constitucionais para o Direito internacional vem a ser o impacto deste sobre as Constituições. Esse impacto manifesta-se, antes de mais, no jus cogens, na medida em que este adstringe os Estados não só nas respectivas relações e com outros sujeitos, mas nas respectivas Constituições. Como estruturante da comunidade internacional, os princípios de jus cogens não podem, por isso, deixar de se sobrepor à Constituição de qualquer Estado enquanto membro dessa comunidade.

O constitucionalista português entende, ante as proposições apresentadas, a necessidade de estruturação da ordem jurídica de maneira uníssona a ponto de não existirem antinomias, exprimindo como consequência jurídica universal no presente período histórico o jus cogens, o qual constituiria um título de legitimidade, senão de validade, de todas as Constituições e traduzir-se-ia em limite ao poder constituinte (MIRANDA, 2011, p. 182).

Ao relativizar os próprios limites do poder constituinte e somatizar um sentido crítico de interpretação constitucional, contemplando a observância de normas imperativas de direito internacional, Miranda (2011, p. 181) não descuidou, em contrapartida, da noção de conformidade entre normas de graus e espeques diferentes, de maneira a se posicionar sobre a necessidade de se preservar uma constante dialética entre a norma internacional e a norma interna, inclusive de matriz constitucional:

Ora, torna-se indiscutível aqui não pequena aproximação à noção de força jurídica específica de certas normas frente a outras e, consequentemente, à noção de conformidade ou desconformidade entre normas de graus diversos. Conceitos nascidos no campo do Direito constitucional irradiam para o Direito das Gentes, assim como, reciprocamente, as adstrições provenientes da inserção dos Estados na vida jurídico-internacional se projetam sobre as Constituições, a começar pelas relações entre ordem interna e ordem internacional.

Parece, ademais, que esse reconhecimento de um necessário intercâmbio entre a norma interna e a norma internacional, de maneira a preservar a unidade do Direito e contemplar o máximo de direitos ao cidadão não é um posicionamento isolado de Miranda. Nomes de respeito como Ruiperez Alamillo albergam essa tendência integracionista ao se manifestar pela necessidade de complementação entre as duas normas jurídicas a fim de solver o pretenso conflito de normas problematizado:

[...] en nuestra opinión, la solución correcta a este interrogante sólo puede hallarse cuando en lugar de proceder, como es habitual, a la contraposición entre el Derecho Constitucional y el Derecho Internacional y, en consecuencia, pretender hacer prevalecer la solución normativa estabelecido en uno sobre la adoptada por el otro, se afirma la absoluta, y necesaria, complementariedad de ambas normaciones para encontrar una solución pacífica y adecuada a nuestro problema. (RUIPEREZ ALAMILLO, 2013, p.112) 
Esse posicionamento encontra respaldo também na Convenção de Viena sobre o Direito dos Tratados, de 1969, que prevê essa possibilidade de baliza do direito internacional no bojo das relações internas, depois de estipular que nenhum Estado pode invocar, após obrigar-se por tratado, o fato de este ter violado disposição de seu direito interno, a não ser que essa manifestação de vontade "diga respeito a uma regra de seu direito interno de importância fundamental" (art. 46). Termo esse que pode ser perfeitamente entendido, sem grandes percalços, como norma constitucional de natureza fundamental.

A essa teoria mista que contempla a integração dos direito interno e internacional de maneira a preservar a unidade do ordenamento jurídico e a essencialidade das normas de jus cogens e de direitos fundamentais, nomeia-se integracionista, a qual se mostra como novidade no debate do conflito de normas estudados, em que pese a mesma possa se valer de premissas e inquietações já consagradas na doutrina sobre o tema.

\section{CONSIDERAÇÕES FINAIS}

Tendo por azo a doutrina pugnada, ora nominada de teoria integracionista, conclui-se que o ponto fulcral para a adoção de um mecanismo para a solução de conflitos entre a norma interna e a norma internacional é a preservação da unidade do ordenamento jurídico. Nesse sentido, reconhece-se que é possível a intersecção entre os espeques interno e internacional da atuação normativa do Estado, sob a égide do intercambismo dialético existente entre as normas em questão, em razão de uma imigração sistemática cada vez mais estreita entre o direito estatal e o direito das gentes.

Reconhece-se, no mais, que as normas de jus cogens e as normas de direito fundamental deverão ter primazia num ordenamento integracionista ante a natureza das normas em questão e ante a previsão normativa, interna e internacional, dessa primazia. Nesse sentido, não haverá óbice à limitação da norma constitucional, originária ou posterior, em decorrência de norma imperativa de direito internacional, embora a primeira tentativa de integralização dessa norma interna com a norma internacional deva sempre ser interpretativa, na busca por uma maior preservação de comandos normativos no sistema vigente.

Observa-se, ainda, que todo o direito internacional convencional, geral ou comum, e mesmo o derivado de organizações internacionais, vigora ou tende a vigorar ainda que as Constituições não o digam de maneira expressa, em razão não só da necessidade de assegurar a integralidade do ordenamento jurídico vigente, mas também em função do alargamento das 
matérias objeto de normas internacionais e de seu sentido protetivo só ter razão de ser quando de sua aplicação, conjuntamente, na ordem interna.

No que tange às leis regulares, de natureza infraconstitucional, as normas de direito internacional tendem a se sobrepor a elas nos ordenamentos jurídicos padrão, pelo princípio geral de Direito segundo o qual está vedado a alguém que se vincule perante outrem se desvincular por ato unilateral, bem como em razão do interesse fundamental de segurança e certeza de harmonização das ordens jurídicas. Raciocínio esse que deve ser adotado, à luz da teoria integracionista, para explicar a necessidade de compatibilização entre a norma interna e a norma internacional, com a consequente necessidade de maior inserção do direito internacional no sistema jurídico interno.

\section{REFERÊNCIAS}

ACCIOLY, Hildebrando; SILVA, Geraldo Eulálio do Nascimento e; CASELLA, Paulo Borba. Manual de direito internacional público. $16^{\mathrm{a}}$ ed. rev., atual. e ampl. São Paulo: Saraiva, 2008.

BARROSO, Luís Roberto. Constituição e tratados internacionais: alguns aspectos da relação entre direito internacional e direito interno. In: DIREITO, Carlos Alberto Menezes; TRINDADE, Antônio Augusto Cançado; PEREIRA, Antônio Alves Celso (orgs.). Novas perspectivas do direito internacional contemporâneo: estudos em homenagem ao professor Celso D. de Albuquerque Mello. Rio de Janeiro: Renovar, 2008.

BOBBIO, Norberto. O positivismo jurídico: lições de filosofia do direito. São Paulo: Ícone, 1995.

Teoria do ordenamento jurídico. $6^{\mathrm{a}}$ ed. Brasília: Editora Universidade de Brasília, 1995.

BRASIL. Decreto $n^{\circ} 7.030$, de 14 de dezembro de 2009. Promulga a Convenção de Viena sobre o Direito dos Tratados, concluída em 23 de maio de 1969, com reserva aos Artigos 25 e 66. Disponível em: < http://www.planalto.gov.br/ccivil_03/_ato2007-2010/2009/decreto/d7030.htm>. Acesso em: 08 ago. 2016. 
CANOTILHO, J. J. Gomes. Direito constitucional e teoria da constituição. $7^{\mathrm{a}}$ ed. Coimbra: Almedina, 2003.

HEGEL, Georg W. F. Princípios da filosofia do Direito. São Leopoldo: Unisinos, 2010.

HELLER, Hermann. La soberanía: contribución a la teoria del derecho estatal y del derecho internacional. 2a ed. Santiago: Fondo de Cultura Económica, 1995.

KELSEN, Hans. Princípios do direito internacional. Ijuí: Unijuí, 2011. Teoria pura do direito. São Paulo: Martins Fontes, 2003.

MAZZUOLI, Valerio de Oliveira. Curso de direito internacional publico. $5^{\mathrm{a}}$ ed. São Paulo: RT, 2011.

MELLO, Celso D. de Albuquerque. Curso de direito internacional publico. $15^{\mathrm{a}} \mathrm{ed}$. rev. e ampl. Rio de Janeiro: Renovar, 2004. vols I e II.

MIRKINE-GUETZEVICH, Boris. Derecho constitucional internacional. Madrid: Reus, 2009.

MIRANDA, Jorge. Teoria do Estado e da constituição. $3^{a}$ ed. rev., atual. e ampl. Rio de Janeiro: Forense, 2011.

PORTELA, Paulo Henrique Gonçalves. Direito internacional público e privado: incluindo noções de direitos humanos e de direito comunitário. $7^{\mathrm{a}}$ ed. rev., ampl. e atual. Salvador: Juspodivm, 2015.

REZEK, José Francisco. Direito internacional público. São Paulo: Saraiva, 2010.

ROMANO, Santi. O ordenamento jurídico. Florianópolis: Fundação Boiteux, 2008. 
A Integração entre o Direito Interno e o Direito Internacional à Luz da Teoria da Constituição: Revisitando as Perspectivas Monista e Dualista do Conflito de Normas Internacionais

RUIPEREZ ALAMILLO, Javier. La nueva reivindicación de la sececión de Cataluña en el contexto normativo de la Constitución española de 1978 y el Tratado de Lisboa. In: UNED. Teoría y realidade constitucional, num. 31, 2013.

SCHMITT, Carl. Teoría de la constitución. Madrid: Alianza Editorial, 2011.

TRIEPEL, Karl Heinrich. As relações entre o direito interno e o direito internacional. Belo Horizonte: S., 1964.

VERDROSS, Alfred. Derecho internacional publico. 6ª ed. Madrid: Aguilar, 1976. 